\title{
Рецензии, отзывы
}

УдК $347.2 / .3$

DOI: 10.14529/law160118

ББК X408.132.11

\section{РЕЦЕНЗИЯ НА МОНОГРАФИЮ Д. В. ЛОРЕНЦА «ВИНДИКАЦИЯ: ЮРИДИЧЕСКАЯ ПРИРОДА И ПРОБЛЕМЫ РЕАЛИЗАЦИИ»}

\author{
А. В. Минбалеев \\ Южно-Уральский государственный университет, г. Челябинск
}

Монографическое исследование Лоренца Дмитрия Владимировича [1] выполнено на тему, актуальность которой обусловлена ролью способов защиты вещных прав в развитии общества, а также тем, что на протяжении последних лет происходит реформирование законодательства РФ в сфере соотношения интересов собственника и добросовестного приобретателя.

Законодательно установленные гарантии свободного осуществления собственниками и иными титульными владельцами своих имущественных прав создают основу для нормального экономического развития любого цивилизованного общества. $\mathrm{B}$ российской юридической науке институт защиты имущественных прав достаточно фундаментально разработан, а правоприменительная практика выработала в основном единообразные подходы в применении норм о защите вещных прав. Тем не менее при анализе судебных дел возникают вопросы как теоретического, так и практического характера, требующие их более детального рассмотрения.

Спорным остается круг лиц, уполномоченных на виндикацию, в частности, речь идет о заявлении виндикационного иска лицами, владеющими вещью в чужих интересах (хранители, перевозчики и пр.), либо неоднозначна возможность признания давностного владельца носителем титула [10, с. 11-16]. Кроме того, согласно ст. 305 ГК РФ собственник приобретает статус ответчика по виндикационному иску, однако последний в первую очередь предназначен именно для защиты прав и интересов собственника. Это формирует потребность в исследовании поссессорной защиты [7, с. 71-76], применяемой независимо от наличия у истца права на вещь.

Проблемным в теории и практике считается вопрос о моменте возникновения винди- кационного требования, когда неизвестна личность нарушителя, что порождает и полемику относительно исчисления срока исковой давности. Нет единого мнения в том, как перемещение вещи от одного нарушителя к другому влияет на срок исковой давности по виндикации. Естественно, не может остаться в стороне и вопрос о последствиях истечения исковой давности, что напрямую связано с проблемой выбытия задавненной вещи из гражданского оборота $[8$, с. 21-24; 14, c. 17-23].

До сих пор не утихают дискуссии о критериях компромисса между интересами собственника и добросовестного приобретателя вещи.

Многие правовые проблемы, рассматриваемые автором в его трудах, исследовались цивилистами и ранее, но либо частично, либо в иной плоскости. Анализ виндикации в качестве обязательственного правоотношения не является традиционным предметом комплексных изысканий. Остается открытым для дальнейшего изучения такой аспект виндикации, как ее ограничение в силу добросовестного приобретения вещи другим лицом. Как правило, соотношение (конкуренция) виндикации с иными притязаниями рассматривается в литературе не как самостоятельная проблема, а как аспект тематики, посвященной реституции или кондикции (неосновательному обогащению). Автор исследует такое соотношение в качестве доказательства недопустимости конкуренции исков, что гарантирует сохранение последствий ограничения виндикации, препятствует необоснованному истребованию вещи у добросовестных субъектов и обеспечивает стабильность гражданского оборота.

O фундаментальности исследования Д. В. Лоренца свидетельствуют солидная на- 
учная юридическая терминология и объемный библиографический список. Работа посвящена не только собственно проблемам виндикации, но и общим вопросам гражданского права относительно природы, классификации и структуры правоотношения. Очевидно внимательное отношение автора не только к изысканиям, посвященным условиям предъявления виндикационного иска и условиям ограничения виндикации (М. В. Аверьянова, Г. Н. Амфитеатров, Р. С. Бевзенко, А. Ерошенко, М. А. Осташевский, Е. Л. Потапенко, В. А. Рахмилович, М. В. Самойлова, К. И. Скловский, Е. А. Суханов, Д. О. Тузов, О. В. Ушаков, Б. Б. Черепахин, А. М. Эрделевский), но и к огромному числу трудов, в которых рассматривается вопрос о соотношении (конкуренции) виндикации с иными способами защиты (В. А. Белов, В. В. Витрянский, О.В. Гутников, С. Е. Донцов, А. В. Климович, А. В. Коновалов, О. С. Иоффе, А.Л. Маковский, С. В. Моргунов, В. В. Ровный, Ю. К. Толстой, Е. М. ТужиловаОрданская, Д. О. Тузов, Е.А. Флейшиц, В. И. Чернышев, А. А. Шамшов, Г. Ф. Шершеневич). Кроме того, проанализированы работы, в которых виндикация исследуется как правоотношение (Е. А. Крашенинников, С. А. Краснова).

Поставленные автором цель и задачи, недостаточная исследованность в науке обозначенных вопросов, выводы в сфере цивилистических категорий (термины «виндикапия», «протекционная давность», «погасительная давность») $[1$, с. 4, 5, 121, 128] составляют актуальность и научную новизну монографии.

Результаты исследования обобщены и представлены в виде 10-ти положений [1, c. 161-163], которые отвечают критериям научной оригинальности, обоснованности и достоверности.

Особое одобрение вызывают следующие моменты работы.

В первую очередь формулируется общее понятие виндикационного правоотношения, которое выведено из анализа юридической природы и структуры данного отношения, затем автор дает понятие виндикационному требованию, которое составляет элемент юридического содержания правоотношения и которое во второй главе исследуется через призму его ограничения различными юридическими фактами (добросовестное приобретение, погасительная и приобретательная дав- ность). Автор наглядно показывает, в чем выражается специфика реализации виндикации в качестве обязательства: а) момент возникновения виндикационного правоотношения зависит от начала психологического взаимодействия виндикната и нарушителя владения, то есть они должны осознавать личность друг друга, чем достигается конкретность юридической связи, а содержание права на виндикацию наполняется определенной моделью поведения конкретного обязанного лица; б) допускается уступка виндикационного требования в качестве способа исполнения традиционных договоров $[1$, с. $17,44,56]$.

Д. В. Лоренц глубоко подходит к исследованию вопроса об основаниях добросовестного приобретения вещи, о значении договора между неуполномоченным отчуждателем и приобретателем. Мы солидарны с автором в том, что необходимо поступательно совершенствовать условия защиты добросовестного приобретателя и расширять их перечень [1, с. 76], поскольку при совокупности обстоятельств такой приобретатель может претендовать на признание за ним статуса собственника, каковым обладал потерпевший до нарушения его владения. Необходимо, исходя из принципов справедливости и разумности, в каждом конкретном случае искать компромисс между интересами потерпевшего и приобретателя, в том числе завладевшего имуществом безвозмездно. Защиту в натуральном виде должен получить тот, чьи возможности возместить убытки минимальны или полностью отсутствуют.

Большое внимание уделяется такому явлению в гражданско-правовых отношениях, как срок исковой давности. Представляется убедительным положение, связывающее возникновение права на защиту с осведомленностью потерпевшего о личности нарушителя, поскольку до этого момента обязанное лицо остается «всяким и каждым». В 2013 году в ГК РФ воплотились идеи автора о том, что для пресечения возможности предъявления виндикационного притязания через неоправданно длительный промежуток времени после нарушения владения помимо срока исковой давности в законе необходима протекционная давность, которую следует исчислять с момента завладения вещью нарушителем, а ее срок должен сочетаться с нормами о приобретательной давности. Исковая давность как юридический срок реализации возникшего 
притязания может начаться и (или) продолжаться только в пределах протекционной давности. О том, что должник может признать долг и тем самым прервать исковую давность в пределах протекционной давности (десять лет с момента нарушения), разъясняется и в новом Постановлении Пленума Верховного Суда РФ от 29 сентября 2015 г. № 43 «О некоторых вопросах, связанных с применением норм Гражданского кодекса Российской Федерации об исковой давности» (п. 8).

Автор своеобразно подходит к исследованию вопросов приобретательной давности, которая, по его мнению, является одним из препятствий реализации виндикационного правоотношения. По-новому решается проблема добросовестности давностного владельца, предлагается рассматривать ее как добропорядочное исполнение лицом своих обязанностей владеть имуществом длительно, открыто, непрерывно как своим собственным. Кроме того, усовершенствован механизм определения срока узукапии в зависимости от осведомленности виндиканта и давностного владельца о личности друг друга: либо в течение исковой давности, либо в пределах специальных видов протекционной давности [1, c. 160].

Об уровне исследования и обоснованности его результатов также свидетельствует их апробация в публикациях, предшествующих монографии $[4 ; 5 ; 6 ; 9 ; 11 ; 12 ; 13 ; 14 ; 15 ; 16$; $20 ; 23]$, и последующих трудах автора $[17 ; 18$; $21 ; 22 ; 24 ; 25]$. Взгляды ученого также распространяются и в процессе творческого преподавания римского и гражданского права [2; 3] на юридическом факультете ЮжноУральского государственного университета.

В то же время изыскание порождает ряд замечаний и вопросов.

1. Д. В. Лоренц разделяет позицию о том, что вещные права существуют вне правоотношений, поскольку управомоченному лицу для удовлетворения своих интересов нет необходимости вступать в юридические связи с иными лицами $[1$, с. 16]. Однако представляется, что реализация любого субъективного права должна уравновешиваться субъективными обязанностями других лиц. Признание субъективного права лишь со стороны государства не совсем достаточно для его осуществления, поэтому оно не способно реализовываться вне правоотношений. Поскольку правообладатель является членом общества, постольку фактическое совершение управомоченным своих действий зависит от его взаимоотношений с участниками гражданского оборота.

2. Автор доказывает, что право на защиту представляет собой требование, а любое отношение по защите есть протекционное обязательство [1, с. 17]. Следует отметить, что из поля зрения выпало право на самозащиту, которое непременно должно рассматриваться как право на собственные действия, что, по всей видимости, является почвой для дальнейшего развития автором своей теории относительно природы протекционных отношений.

3. В качестве концептуальной идеи автор рассматривает виндикацию как протекционное правоотношение. Но в доктрине подобные отношения принято именовать охранительными. В связи с этим хотелось бы указать, что в монографии не нашли свое отражение рассуждения по поводу того, почему виндикацию следует относить именно к протекционным отношениям и почему не подходит категория «охранительное». Справедливости ради обратим внимание на то, что данное замечание затрагивает необходимость услышать авторское понимание соотношения таких юридических субстанций, как охрана и защита.

Высказанные предложения никоим образом не влияют на общую положительную оценку монографии.

Содержание изыскания позволяет сделать вывод о том, что работа является целостным, завершенным научным исследованием, содержащим ценные положения для науки гражданского права.

Монография Д. В. Лоренца на тему «Виндикация: юридическая природа и проблемы реализации» может быть рекомендована научным работникам, преподавателям, аспирантам, студентам юридических вузов и факультетов, практикующим юристам, а также всем интересующимся современными проблемами российской и зарубежной цивилистики.

\section{Литература}

1. Лоренц, Д. В. Виндикация: юридическая природа и проблемы реализации: монография / Д. В. Лоренц. - М.: Инфра-М, 2015. $164 \mathrm{c}$.

2. Лоренц, Д. В. Инновационная андрагогика на примере дисциплины «Гражданское 
право»: учебно-методическое пособие Д. В. Лоренц. - М.: ИНФРА-М, 2013. - 84 с.

3. Лоренц, Д. В. Креативная педагогика на примере дисциплины «Римское частное право»: учебно-методическое пособие / Д. В. Лоренц. - М.: ИНФРА-М, 2014. - 112 с.

4. Лоренц, Д. В. Виндикация: юридическая природа и проблемы реализации: дис. ... канд. юрид. наук / Д. В. Лоренц. - Краснодар, 2008. - 210 c.

5. Лоренц, Д. В. Виндикация: юридическая природа и проблемы реализации: автореферат дис. ... канд. юрид. наук / Д. В. Лоренц. - Краснодар, 2008. - 25 с.

6. Лоренц, Д. В. Проблемы юридической квалификации кондикционных и деликтных правопритязаний / Д. В. Лоренц // Юрист. 2008. - № 3. - С. 29-32.

7. Лоренц, Д. В. О владельческом (поссессорном) притязании / Д. В. Лоренц // Законодательство. - 2009. - № 1. - С. 11-16.

8. Лоренц, Д. В. Особенности применения исковой давности при виндикации имущества / Д. В. Лоренц // Арбитражный и гражданский процесс. - 2009. - № 1. - С. 21-24.

9. Лоренц, Д. В. Юридическая природа реституции / Д. В. Лоренц // Законы России: опыт, анализ, практика. - 2009. - № 12. C. 112-116.

10. Лоренц, Д. В. Субъекты права на виндикацию в свете реформы гражданского законодательства / Д. В. Лоренц // Современное право. - 2011. -№ 3. - С. 71-76.

11. Лоренц, Д. В. Система гражданскоправовых притязаний и проблема их конкуренции / Д. В. Лоренц // Гражданское право. 2008. - № 4. - C. 7-10.

12. Лоренц, Д. В. К дискуссии о соотношении виндикации и кондикции / Д. В. Лоренц // Нотариальный вестник. - 2008. - № 10. - C. 34-39.

13. Лоренц, Д. В. К вопросу о виндикационном правоотношении / Д. В. Лоренц // Вестник Челябинского государственного университета. Серия «Право». - 2008. - Вып. 17. - № 31 (132). - С. 79-85.

14. Лоренц, Д. В. К дискуссии о добросовестности давностного владельца / Д. В. Лоренц // Законодательство. - 2009. - № 9. C. 17-23.
15. Лоренц, Д. В. Цессия виндикационного притязания / Д. В. Лоренц // Современное право. - 2009. - № 9. - С. 70-74.

16. Лоренц, Д. В. Природа добросовестного приобретения вещи: сложный юридический факт или сделка / Д. В. Лоренц // Гражданское право. - 2011. -№ 2. - С. 20-22.

17. Лоренц, Д. В. Особенности защиты имущественных прав наследников / Д. В. Лоренц // Наследственное право. - 2012. - № 3. C. 21-28.

18. Лоренц, Д. В. Владельческая защита: зарубежный опыт, российская история и модернизация ГК РФ / Д. В. Лоренц // Современное право. - 2012. - № 12. - С. 50-56.

19. Лоренц, Д. В. Условия вступления наследников в давностное владение / Д. В. Лоренц // Наследственное право. - 2008. - № 3. C. $13-16$.

20. Лоренц, Д. В. К вопросу о действительности сделки между неуполномоченным отчуждателем и приобретателем / Д. В. Лоренц // Нотариальный вестник. - 2008. - № 12. - C. 7-11.

21. Лоренц, Д. В. Восстановление корпоративного контроля: возвращение доли участия или признание права на долю в уставном капитале? / Д. В. Лоренц // Хозяйство и право. -2015 . - № 8. - С. 3-16.

22. Лоренц, Д. В. Протекционная давность как уголовно-цивилистическая категория / Д. В. Лоренц // Власть закона. - 2015. № 2. - С. 113-119.

23. Лоренц, Д. В. К проблеме «абсолютного правоотношения» / Д. В. Лоренц // Вестник Южно-Уральского государственного университета. Серия «Право». - 2009. - Вып. 17. - № 6 (139). - С. 52-57.

24. Лоренц, Д. В. Право личного пользовладения (узуфрукт): перспективы в России и опыт зарубежных стран // Вестник ЮжноУральского государственного университета. Серия «Право». - 2013. - Т. 13. - № 2. C. 55-58.

25. Лоренц, Д. В. Отзыв ведущей организации о диссертации Р. В. Рыбакова «Право собственности хозяйственных обществ» // Вестник Южно-Уральского государственного университета. Серия «Право». - 2014. - Т. 14. - № 3. - C. 114-118. 
Минбалеев Алексей Владимирович - доктор юридических наук, доцент, профессор кафедры конституционного и административного права, Южно-Уральский государственный университет, г. Челябинск. E-mail: alexmin@bk.ru.

Статья поступила в редакцию 19 ноября 20152.

DOI: 10.14529/law160118

\title{
REVIEW OF THE MONOGRAPH OF D. V. LORENTS «VINDICATION: A LEGAL NATURE AND PROBLEMS OF REALIZATION»
}

\author{
A. V. Minbaleev \\ South Ural State University, Chelyabinsk, Russian Federation
}

\section{References}

1. Lorents D. V. Vindikatsiya: yuridicheskaya priroda i problemy realizatsii: Monografiya [Vindication: legal nature and problems of realization: Monograph]. Moscow, 2015, $164 \mathrm{p}$.

2. Lorents D. V. Innovatsionnaya andragogika na primere distsipli-ny "Grazhdanskoe pravo" [Innovative andragogics an example of discipline "Civil Law"]. Moscow, 2013, 84 p.

3. Lorents D. V. Kreativnaya pedagogika na primere distsipliny "Rim-skoe chastnoe pravo" [Creative pedagogy to a discipline example "Roman Private Law"]. Moscow, 2014, 112 p.

4. Lorents D. V. Vindikatsiya: yuridicheskaya priroda i problemy realizatsii: dis. ... cand. yurid. nauk [Vindication: legal nature and problems of realization. Diss. Kand. (Law)]. Krasnodar, 2008, $210 \mathrm{p}$.

5. Lorents D. V. Vindikatsiya: yuridicheskaya priroda i problemy realizatsii: avtoreferat dis. ... cand. yurid. nauk [Vindication: legal nature and problems of realization. Author's abstract Diss. Kand. (Law)]. Krasnodar, 2008, 25 p.

6. Lorents D. V. [Problems of legal qualification condiction and tort legal entitlement]. Yurist [Lawyer], 2008, no. 3, pp. 29-32. (in Russ.)

7. Lorents D. V. [About possessory claims]. Zakonodatel'stvo [Legislation], 2009, no. 1, pp. 1116. (in Russ.)

8. Lorents D. V. [Features of the application of the limitation period when vindication of the property]. Arbitrazhnyy i grazhdanskiy protsess [Arbitration and civil procedure], 2009, no. 1, pp. 21-24. (in Russ.)

9. Lorents D. V. [The legal nature of the restitution]. Zakony Rossii: opyt, analiz, praktika [Laws of Russia: experience, analysis, and practice], 2009, no. 12, pp. 112-116. (in Russ.)

10. Lorents D. V. [The subjects of the right to vindication in the light of the reform of civil law]. Sovremennoe parvo [Modern law], 2011, no. 3, pp. 71-76. (in Russ.)

11. Lorents D. V. [The system of civil claims and the issue of competition]. Grazhdanskoe parvo [Civil law], 2008, no. 4, pp. 7-10. (in Russ.)

12. Lorents D. V. [For discussion of the relationship between vindication and condiction]. Notarial'nyy vestnik [Notary Bulletin], 2008, no. 10, pp. 34-39. (in Russ.)

13. Lorents D. V. [On the question of vindication Relationship]. Vestnik Chelyabinskogo gosudarstvennogo universiteta. Nauchnyy zhurnal. Seriya "Pravo" [Bulletin of Chelyabinsk State University. Science Magazine. A series of "Law"], 2008, vol. 17, no. 31 (132), pp. 79-85. (in Russ.)

14. Lorents D. V. [Discussion on the integrity owner]. Zakonodatel'stvo [Legislation], 2009, no. 9, pp. 17-23. (in Russ.)

15. Lorents D. V. [Assignment of claims vindication]. Sovremennoe parvo [Modern law], 2009, no. 9, pp. 70-74. (in Russ.) 
16. Lorents D. V. [The nature of the acquisition of good things: complex legal fact or transaction]. Grazhdanskoe parvo [Civil law], 2011, no. 2, pp. 20-22. (in Russ.)

17. Lorents D. V. [Features to protect the property rights of heirs]. Nasledstvennoe parvo [Inheritance Law], 2012, no. 3, pp. 21-28. (in Russ.)

18. Lorents D. V. [Possessory protection: international experience, the history of Russia and the modernization of the Civil Code]. Sovremennoe parvo [Modern law], 2012, no. 12, pp. 50-56. (in Russ.)

19. Lorents D. V. [Terms and conditions of entry of heirs in possession]. Nasledstvennoe parvo [Inheritance Law], 2008, no. 3, pp. 13-16. (in Russ.)

20. Lorents D. V. [To a question on the validity of transactions between non-authorized transferor and the purchaser]. Notarial'nyy vestnik [Notary Bulletin], 2008, no. 12, pp. 7 - 11. (in Russ.)

21. Lorents D. V. [Restoration of corporate control: the return of interest or the recognition of the right to a share in the authorized capital?]. Khozyaystvo i pravo [Economy and law], 2015, no. 8, pp. 3-16. (in Russ.)

22. Lorents D. V. [Protectional prescription as a criminal civil category]. Vlast' zakona [Rule of law], 2015, no. 2, pp. 113-119. (in Russ.)

23. Lorents D. V. [On the problem of «absolute legal relation»]. Vestnik Juzhno-Ural'skogo gosudarstvennogo universiteta. Serija «Pravo» [Bulletin of the South Ural State University. Series "Law"], 2009, vol. 17, no. 6 (139), pp. 52-57. (in Russ.)

24. Lorents D. V. [Right of personal use-possession (usufruct): perspectives in Russia and the experience of foreign countries]. Vestnik Juzhno-Ural'skogo gosudarstvennogo universiteta. Serija "Pravo" [Bulletin of the South Ural State University. Series "Law"], 2013, vol. 13, no. 2, pp. 55-58. (in Russ.)

25. Lorents D. V. [The leading organization review on the thesis R.V. Rybakov "Title of economic entities»]. Vestnik Juzhno-Ural'skogo gosudarstvennogo universiteta. Serija "Pravo" [Bulletin of the South Ural State University. Series "Law”], 2014, vol. 14, no. 3, pp. 114-118. (in Russ.)

Aleksey Vladimirovich Minbaleev - Doctor of Law, Professor of Constitutional and Administrative Law Department, South Ural State University, Chelyabinsk, Russian Federation. E-mail: alexmin@bk.ru.

Received 19 November 2015.

\section{ОБРАЗЕЦ ЦИТИРОВАНИЯ}

Минбалеев, А. В. Рецензия на монографию Д. В. Лоренца «Виндикация: юридическая природа и проблемы реализации» / А. В. Минбалеев // Вестник ЮУрГУ. Серия «Право». - 2016. - Т. 16, № 1. - С. 108-113. DOI: 10.14529/law160118.

\section{FOR CITATION}

Minbaleev A. V. Review of the monograph of D. V. Lorents "Vindication: a legal nature and problems of realization". Bulletin of the South Ural State University. Ser. Law, 2016, vol. 16, no. 1, pp. 108-113. (in Russ.) DOI: $10.14529 /$ law160118. 